\title{
Prostate Capsule
}

National Cancer Institute

\section{Source}

National Cancer Institute. Prostate Capsule. NCI Thesaurus. Code C13086.

The membrane the surrounds the prostate gland. 